\title{
Removal of ethyl acetate, $n$-hexane and toluene from waste air in a membrane bioreactor under continuous and intermittent feeding conditions
}

\author{
F. Javier Álvarez-Hornos, Diëgo Volckaert, Philippe M. Heynderickx, \\ Herman Van Langenhove \\ Research Group EnVOC, Faculty of Bioscience Engineering, Ghent \\ University, Coupure Links 653, 9000 Ghent, Belgium
}

\begin{abstract}
Ethyl acetate, n-hexane and toluene removal from an air stream was carried out using a flat composite membrane bioreactor. The composite membrane consisted of a dense polydimethylsiloxane top layer with an average thickness of $1.5 \mu \mathrm{m}$ supported by a polyacrylonitrile layer $(50 \mu \mathrm{m})$. The membrane bioreactor (MBR) was operated during 4 months under continuous and intermittent loading conditions. Removal efficiencies higher than $99 \%$ were obtained for inlet loads up to $200 \mathrm{~g} \mathrm{~m}^{-3} \mathrm{~h}^{-1}$ and empty bed residence times as short as $15 \mathrm{~s}$ for ethyl acetate. A maximum elimination capacity of $75 \mathrm{~g} \mathrm{~m}^{-3} \mathrm{~h}^{-1}(\mathrm{RE} \sim 66 \%)$ at an EBRT of $60 \mathrm{~s}$ was obtained for toluene. The system was unable to degrade n-hexane when a 1:1:1 ethyl acetate:n-hexane:toluene was supplied. The intermittent loading experiments illustrated the capacity of the MBR to put up with intermittent feeding conditions $\left(16 \mathrm{~h} \mathrm{day}^{-1}, 5\right.$ days week ${ }^{-}$ ${ }^{1}$ ) and recover quickly after a period without VOC feeding. Ethyl acetate was not detected in the membrane gas outlet. $\mathrm{CO}_{2}$ production recovered within $1-2 \mathrm{~h}$ and $12 \mathrm{~h}$ when organic compound supply turned off during a night and a weekend, respectively.
\end{abstract}

\section{INTRODUCTION}

The increasingly restrictive environmental regulations related to emissions of volatile organic compounds (VOCs) from industrial sources, have led industrial sites to demand efficient and cost-effective air pollution treatment technologies. Among the available technologies, vapour phase biological treatment has been classified as Best Available Technologies for the abatement of low VOC concentration waste gas streams in the chemical sector by the European IPPC Bureau (European Commission, 2003). These biotechnologies are a potential alternative to conventional physicochemical processes due to low operating cost, low energy requirement, and the absence of waste products that require further treatment or disposal. Among these ones, the biofilters and biotrickling filters have been widely studied and applied for the abatement of VOCs from waste gases (Kennes et al., 2009; Mudliar et al., 2010), presenting some limitations such as control of the moisture content, treatment of hydrophobic compounds (Kumar et al., 2010) and large size requirements, especially for biofilters (Devinny et al., 1999). 
The membrane bioreactor (MBR) for waste gas treatment is a relatively new technology that provides a large surface area for VOC mass transfer and makes the separation of gas and liquid phases possible. Pollutants diffuse through the membrane and are degraded by the microorganisms presented in the biofilm. Nutrients are supplied by the continuous recirculation liquid. The literature about the removal of waste gas contaminated with VOCs using membrane bioreactors is limited (England et al., 2005; Ergas et al., 1999; Kumar et al., 2009). For example, Attaway et al. (2002) studied the removal of BTEX in a microporous poly-propylene hollow-fibre MBR, achieving an average removal efficiency (RE) of $61 \%$ for an approximately inlet concentration of $3 \mathrm{~g}$ $\mathrm{m}^{-3}$ working at empty bed residence times (EBRTs) between 8 and $16 \mathrm{~s}$. The available data, which are mainly focused on aromatic compounds, indicate that, in general, the membrane bioreactor could potentially be more effective than conventional biosystems. Although it still requires further investigation and optimization with complex VOCs mixtures and/or transient conditions. In this sense, most of industrial VOC gaseous emissions present flux variations, and daily and weekly rotations in the production and little attention has been focus on the research on characterization of the transient response of MBR in removing VOCs in air, even though these load fluctuations are challenging for biological waste gas treatment systems as they are sensitive to transient feed conditions and process shutdowns (Koutinas et al., 2006).

The purpose of the present research was to evaluate the performance of a composite membrane bioreactor to treat waste gas contaminated with two VOC mixtures, a 1:1 (wt) ethyl acetate and toluene mixture and a 1:1:1 (wt) of ethyl acetate, n-hexane and toluene mixture. The following objectives were taken in consideration: (1) to study the steady-state removal of the two VOC mixtures in a flat composite MBR; (2) to obtain the value of the maximum EC and its variation with the EBRT; (3) to evaluate the response of the MBR to intermittent feeding conditions (16-h on/8-h off, 5 days/week), and pulse-step changes in inlet concentration for the removal of the ethyl acetate:toluene mixture.

\section{MATERIALS AND METHODS}

\subsection{Membrane materials}

A commercially available composite membrane was provided by GKSS Forschungszentrum Geesthacht (Germany), consisted of polydimethylsiloxane (PDMS) as the hydrophobic dense top layer material with an average thickness of $1.5 \mu \mathrm{m}$ and polyacrylonitrile (PAN) as the hydrophobic support layer with a thickness around 50 $\mu \mathrm{m}$.

\subsection{Membrane bioreactor system and operating conditions}

A schematic of the membrane bioreactor set-up is shown in Figure 1. The MBR, which was placed in an isothermal chamber at $23{ }^{\circ} \mathrm{C}$, consisted of two identical compartments made of Perspex. Each compartment had four channels, length $20 \mathrm{~cm}$, width $5 \mathrm{~mm}$, and height $2 \mathrm{~mm}$. The membrane was clamped between both compartments, resulting in a contact area of $40 \mathrm{~cm}^{2}$ (specific membrane surface area of $500 \mathrm{~m}^{2} \mathrm{~m}^{-3}$ ). Dry air, polluted with the VOC by using a syringe pump (New Era, infusion/withdraw NE 1000 model, USA), was flowed along the porous membrane side. The air flow was adjusted using a mass flow controller (Brooks Instruments, USA). The recirculation liquid was continuously introduced counter to the air flow through the dense membrane side. The liquid flow rate was adjusted to $75 \mathrm{~cm}^{3} \mathrm{~min}^{-1}$ by a peristaltic pump (Masterflex, Cole 
Palmer, USA). The recirculation bottle was placed in a thermostatic water bath at $23{ }^{\circ} \mathrm{C}$. A scouring system was monthly used as clean-up technique to avoid blockages of the liquid channels at the dense membrane side. The system consisted of a syringe connected to the liquid side in order to create a pulse of air to remove the excess of biomass attached on the membrane, transferring the removed biomass to the recirculation bottle.

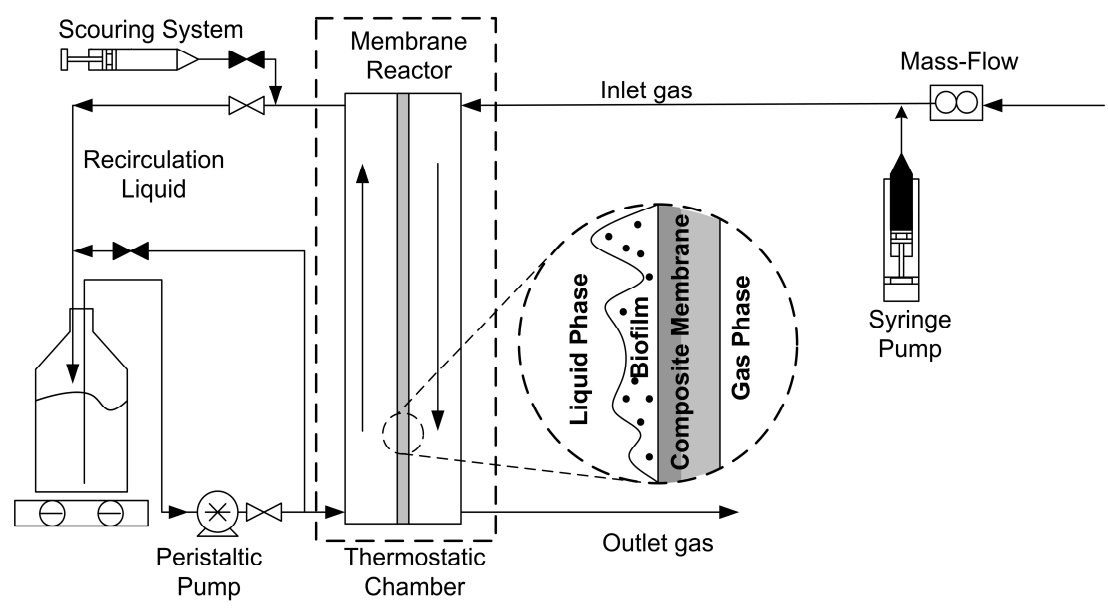

Figure 1. Schematic of the membrane reactor set-up.

The necessary macro and micronutrients were incorporated using a $\mathrm{pH}$ buffered nutrient solution containing $\mathrm{KNO}_{3}, 10.7 \mathrm{~g} \mathrm{~L}^{-1}, \mathrm{KH}_{2} \mathrm{PO}_{4}, 3.0 \mathrm{~g} \mathrm{~L}^{-1}, \mathrm{~K}_{2} \mathrm{HPO}_{4}, 3.0 \mathrm{~g} \mathrm{~L}^{-1}$, $\mathrm{MgSO}_{4} \cdot 7 \mathrm{H}_{2} \mathrm{O}, 0.5 \mathrm{~g} \mathrm{~L}^{-1}, \mathrm{P}, \mathrm{Ca}, \mathrm{Fe}, \mathrm{Zn}, \mathrm{Co}, \mathrm{Mn}, \mathrm{Mo}, \mathrm{Ni}, \mathrm{B}$ and vitamins at trace doses (ranged between 1 and $200 \mathrm{mg} \mathrm{L}^{-1}$ for trace elements and between 10 and $3000 \mu \mathrm{g} \mathrm{L}^{-1}$ for vitamins). The flow rate of the nutrient solution supplied to the MBR was adjusted to keep nitrogen concentrations $>20 \mathrm{mg} \mathrm{N} \mathrm{L}^{-1}$ in the recirculation solution. The MBR was inoculated with a mixed microbial culture (obtained from activated sludge which was adapted to the compounds to be treated). For acclimation of the microbes, the ethyl acetate:toluene mixture was continuously fed to an activated sludge from a Wastewater Treatment Plant (Ossemeersen, Ghent).

Table 1. Design operational parameters for MBR experiments

\begin{tabular}{|c|c|c|c|c|c|c|c|c|c|}
\hline & \multicolumn{7}{|c|}{ Stage A } & \multicolumn{2}{|c|}{ Stage B } \\
\hline & A1 & $\mathrm{A} 2$ & A3 & A4 & A5 & A6 & A7 & B1 & B2 \\
\hline VOC mixture $^{a}$ & $\mathrm{I}$ & $\mathrm{I}$ & $\mathrm{I}$ & $\mathrm{I}$ & II & II & II & $\mathrm{I}$ & $\mathrm{I}$ \\
\hline Total inlet load ${ }^{\mathrm{b}}, \mathrm{g} \mathrm{m}^{-3} \mathrm{~h}^{-1}$ & 100 & 200 & 200 & 400 & 150 & 75 & 150 & 100 & 100 \\
\hline $\mathrm{EBRT}^{\mathrm{c}}$ & 30 & 15 & 30 & 15 & 30 & 60 & 60 & 60 & 30 \\
\hline Feed interval & & & & & & & & & \\
\hline hours day ${ }^{-1}$ & 24 & 24 & 24 & 24 & 24 & 24 & 24 & 16 & 16 \\
\hline days week $^{-1}$ & 7 & 7 & 7 & 7 & 7 & 7 & 7 & 5 & 5 \\
\hline
\end{tabular}

The membrane bioreactor was operated during 4 months. The experiments were divided in two stages. The operational parameters are summarized in Table 1. During the stage A, a study under steady-state conditions was carried out to evaluate the influence of the 
flow rate at relatively medium-high inlet load on the MBR's performance treating both ethyl acetate:toluene and ethyl acetate:n-hexane:toluene mixtures. Several operational conditions were tested: total VOC concentrations varied from $500 \mathrm{mg} \mathrm{C} \mathrm{Nm}^{-3}$ to 2500 $\mathrm{mg} \mathrm{C} \mathrm{Nm}{ }^{-3}$ at EBRTs between 15 and $60 \mathrm{~s}$. Stage B was applied in order to simulate the shift work practices of some industrial facilities, in which overnight and weekend shutdown periods are considered. In this stage the ethyl acetate:toluene mixture was intermittently fed to the system $\left(16 \mathrm{~h} \mathrm{day}^{-1}, 5\right.$ day $\left.\mathrm{week}^{-1}\right)$. During this stage, additional experiments were developed to study the dynamic response of the MBR to shock loadings. On two different days, the MBR were exposed to 1-h peak of a 1.5- and 2-fold increase in its baseline concentration.

\subsection{Analytical techniques}

The VOC gas concentrations from the sampling ports located at the inlet and the outlet gas stream of the MBR were daily monitored by using a gas chromatograph (6890 Series, Agilent Technologies, USA) equipped with a flame ionization detector and an HP-5 capillary column $(30 \mathrm{~m} \times 0.32 \mathrm{~mm} \times 0.25 \mu \mathrm{m}$, Agilent Technologies, USA). The gas carrier was helium at a flow-rate of $2.3 \mathrm{~cm}^{3} \mathrm{~min}^{-1}$. The injector, oven and detector temperatures were 200,35 and $250{ }^{\circ} \mathrm{C}$, respectively. Gas samples were taken using a 1.0 $\mathrm{ml} \mathrm{GASTIGHT}^{\circledR}$ syringe and analyzed by duplicate. The VOC concentrations in the recirculation solution were weekly determined according to Álvarez-Hornos et al. (2011). The $\mathrm{CO}_{2}$ concentration at the gas stream was measured by using a CARBOCAP $^{\circledR}$ carbon dioxide analyser (GM70 model, Vaisala, Finland). The $\mathrm{pH}$, conductivity and dissolve oxygen were monitored daily for the recirculation solution as well. Nitrate and phosphate concentrations were periodically measured with Nanocolor ${ }^{\circledR}$ tube tests 0-80 and 0-65, respectively (Macherey-Nagel, Germany).

\section{RESULTS AND DISCUSSION}

\subsection{Continuous loading phase}

The performance parameters of the membrane bioreactor for the continuous loading phase are summarised in Table 2 for the different stages of the experimental plan (daily measured). The average values of the conductivity and the $\mathrm{pH}$ of the recirculation solution were $0.8 \pm 0.3 \mathrm{mS} \mathrm{cm}^{-1}$ and $7.6 \pm 0.6$, respectively. The dissolved oxygen in the solution was always higher than $6.0 \mathrm{mg} \mathrm{O}_{2} \mathrm{~L}^{-1}$.

Table 2. Operational and performance parameters on the different continuous loading phases

\begin{tabular}{lrcccccc}
\hline & Days & EBRT $^{\mathrm{a}}, \mathrm{s}$ & $\begin{array}{c}\text { Total IL }^{\mathrm{a}} \\
\mathrm{g} \mathrm{m}^{-3} \mathrm{~h}^{-1}\end{array}$ & $\begin{array}{c}\text { Total EC }_{\mathrm{a} \mathrm{m}}^{-3} \mathrm{~h}^{-1} \\
\mathrm{~g}^{\mathrm{a}},\end{array}$ & $\begin{array}{c}\mathrm{RE}, \% \\
\text { Ethyl Acetate }\end{array}$ & $\begin{array}{c}\mathrm{RE} \% \\
\mathrm{n} \text {-Hexane }\end{array}$ & $\begin{array}{c}\text { RE, \% } \\
\text { Toluene }\end{array}$ \\
\hline Stage A1 & $0-17$ & $30.6 \pm 0.5$ & $105 \pm 15$ & $90 \pm 15$ & $>99.5$ & - & $70.2 \pm 11.4$ \\
Stage A2 & $17-25$ & $15.6 \pm 0.3$ & $200 \pm 19$ & $150 \pm 13$ & $>99.9$ & - & $50.9 \pm 4.3$ \\
Stage A3 & $25-32$ & $30.9 \pm 0.2$ & $186 \pm 27$ & $151 \pm 23$ & $>99.9$ & - & $62.8 \pm 2.3$ \\
Stage A4 & $32-38$ & $15.6 \pm 0.1$ & $389 \pm 21$ & $250 \pm 18$ & $>99.9$ & - & $30.7 \pm 3.6$ \\
Stage A5 & $38-54$ & $30.5 \pm 0.1$ & $164 \pm 17$ & $95 \pm 11$ & $>99.9$ & $3.5 \pm 2.5$ & $66.8 \pm 3.2$ \\
Stage A7 & $54-59$ & $64.3 \pm 0.6$ & $73 \pm 6$ & $49 \pm 5$ & $>99.9$ & $3.3 \pm 3.3$ & $92.4 \pm 0.5$ \\
\hline
\end{tabular}

${ }^{\text {a }}$ Calculated by using the reactor volume of the gas side.

Inoculation of the MBR (day 0, stage A1) was performed by recirculating $250 \mathrm{~mL}$ of the inoculum along the dense side of the membrane during 48 hours. The system was operated at an EBRT of $30 \mathrm{~s}$ with an inlet load of approximately $100 \mathrm{~g} \mathrm{~m}^{-3} \mathrm{~h}^{-1}$ for the 
1:1 (wt) ethyl acetate:toluene mixture. Stable REs were achieved in $24 \mathrm{~h}$, with complete degradation of ethyl acetate, indicating the suitable development of the biofilm on the dense membrane layer. After 2 days, the microbial suspension was totally replaced by fresh solution with a nitrogen concentration of $20 \mathrm{mg} \mathrm{N} \mathrm{L}^{-1}$. After phase A1, different stages (A2 to A4) were established with increasing IL of 200 and $400 \mathrm{~g} \mathrm{~m}^{-3} \mathrm{~h}^{-1}$ for two EBRTs (30 and $15 \mathrm{~s})$. In the case of ethyl acetate, complete removal was obtained, even for the most exigent applied conditions, $15 \mathrm{~s}$ of EBRT and $200 \mathrm{~g}_{\text {ethyl acetate }} \mathrm{m}^{-3} \mathrm{~h}^{-1}$. For the toluene, the increase in the EBRT caused an improvement in the toluene RE of the MBR system. For example, at a toluene IL approximately of $100 \mathrm{~g} \mathrm{~m}^{-3} \mathrm{~h}^{-1}$, average RE values increased from 50.9 to $62.8 \%$ for EBRTs of 15 and $30 \mathrm{~s}$, respectively (stages A2 and A3). At day 38, the recirculation liquid was totally replaced by fresh solution $(\sim 20$ mg N L $\left.{ }^{-1}\right)$. During the stages A5 to A7, the air was contaminated with the $(1: 1: 1)$ ethyl acetate:n-hexane:toluene mixture. The results showed no removal of $n$ - in the MBR, indicating that for this compound a specialised bacteria or fungi consortium instead of pre-adapted sludge should be used (Hassan and Sorial, 2010) and/or the microorganisms prefer ethyl acetate and toluene instead of hexane when a mixture is supplied. In the case of ethyl acetate and toluene, similar performance of the MBR as that obtained during stages A1 - A4 was observed. It has to be mentioned that neither ethyl acetate nor toluene nor by-products were detected in the recirculation solution throughout all experimental period.

The elimination capacity (EC) as function of inlet load (IL), both expressed as grams of each individual compound, at different EBRTs is plotted in Figure 2 for (a) ethyl acetate and (b) toluene.
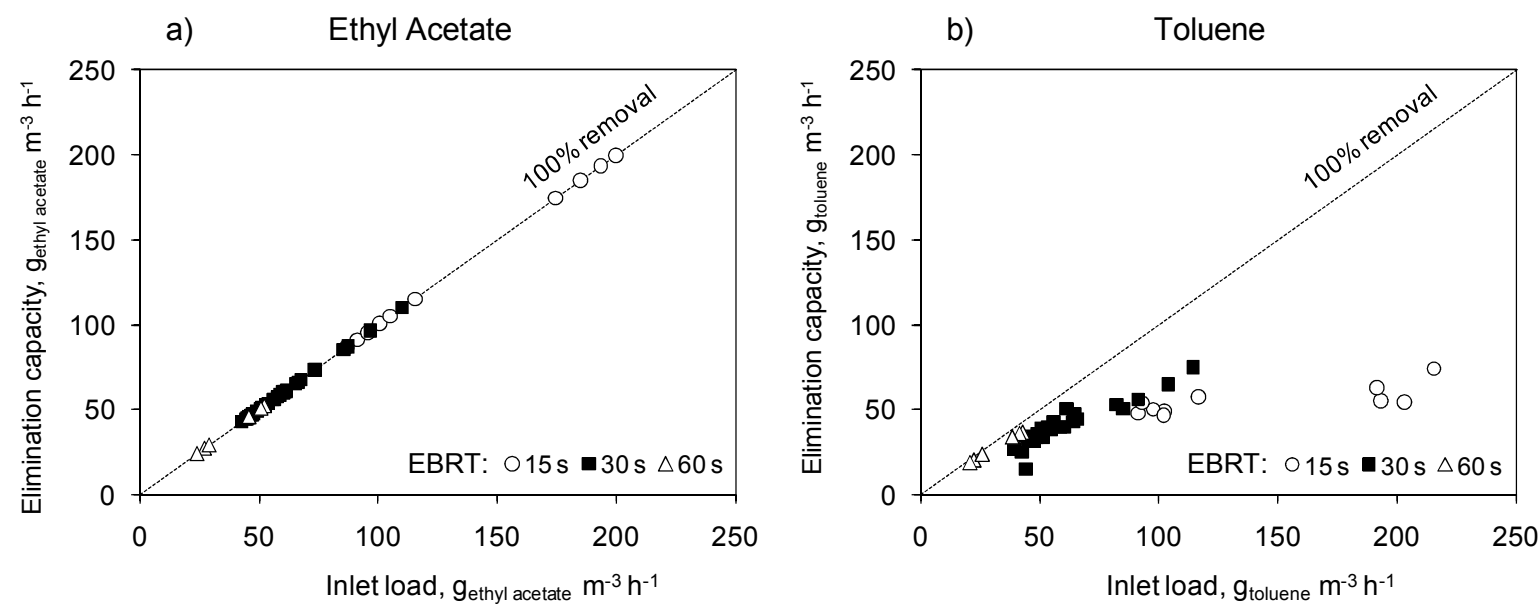

Figure 2. EC vs. IL at different EBRTs for (a) ethyl acetate and (b) toluene.

Results shown in Figure 2 are consistent with the biodegradability of the compounds, greater EC for ethyl acetate than toluene. The proportionality between IL and EC was reached for ILs up to $200 \mathrm{~g} \mathrm{~m}^{-3} \mathrm{~h}^{-1}$ and $50 \mathrm{~g} \mathrm{~m}^{-3} \mathrm{~h}^{-1}$ for ethyl acetate and toluene, respectively. In the case of ethyl acetate, no influence of the applied EBRT (which ranged between 15 and $60 \mathrm{~s}$ ) on EC values was observed. However, in the case of toluene the effect of EBRT on the EC values can be observed for ILs approximately of $115 \mathrm{~g} \mathrm{~m}^{-3} \mathrm{~h}^{-1}$, with EC values of $75 \mathrm{~g} \mathrm{~m}^{-3} \mathrm{~h}^{-1}(\mathrm{RE}=66 \%)$ for an EBRT of $60 \mathrm{~s}$ and $57 \mathrm{~g}$ $\mathrm{m}^{-3} \mathrm{~h}^{-1}(\mathrm{RE}=48 \%)$ for $15 \mathrm{~s}$. In a previous work (Álvarez-Hornos et al., 2011) the authors studied the removal of ethyl acetate in an MBR using a PDMS/PAN composite 
membrane with a PDMS thickness of $0.3 \mu \mathrm{m}$. The maximum EC was $150 \mathrm{~g} \mathrm{~m}^{-3} \mathrm{~h}^{-1}(\mathrm{RE}$ $=32 \%$ ) at an EBRT of $15 \mathrm{~s}$. The comparison with the maximum EC obtained in this study $\left(200 \mathrm{~g} \mathrm{~m}^{-3} \mathrm{~h}^{-1}, \mathrm{RE} \sim 100 \%, \mathrm{EBRT}=15 \mathrm{~s}\right)$ indicates that a higher PDMS thickness $(1.5 \mu \mathrm{m}$ instead of $0.3 \mu \mathrm{m})$ improved the performance of the system, corroborating the hypothesis that water permeated through the composite membrane with PDMS thickness of $0.3 \mu \mathrm{m}$ and hampered mass transfer over the membrane. It is worth noting that the performance of the flat membrane bioreactor $\left(500 \mathrm{~m}^{2} \mathrm{~m}^{-3}\right)$ could be enhanced when a reactor configuration with large surface area, e.g. hollow-fibre (up to $30000 \mathrm{~m}^{2}$ $\mathrm{m}^{-3}$ ), are selected (Kim and Kim, 2005).

\subsection{Intermittent loading phase}

The results of the membrane reactor monitoring during the intermittent loading phase $\left(16\right.$ h day $^{-1}, 5$ day week $\left.{ }^{-1}\right)$ are presented in Figure 3. Two EBRTs were applied, $60 \mathrm{~s}$ and 30 s during stage B1 and B2, respectively. As can be observed, ethyl acetate was completely removed such as previously occurred during continuous loading experiments. In the case of toluene, deterioration of the performance for this compound in comparison with the continuous loading performance was not detected. For example, in stage B2 (30 s of EBRT and $50 \mathrm{~g}_{\text {toluene }} \mathrm{m}^{-3} \mathrm{~h}^{-1}$ ) an average toluene RE of $64.3 \%$ was observed, similar as that obtained during stage A3 (30 s of EBRT and $50 \mathrm{~g}_{\text {toluene }} \mathrm{m}^{-3} \mathrm{~h}^{-1}$ ) with a value of $62.8 \%$. These data show the robustness and the capacity of the MBR to handle shift work and intermittent pattern emissions.

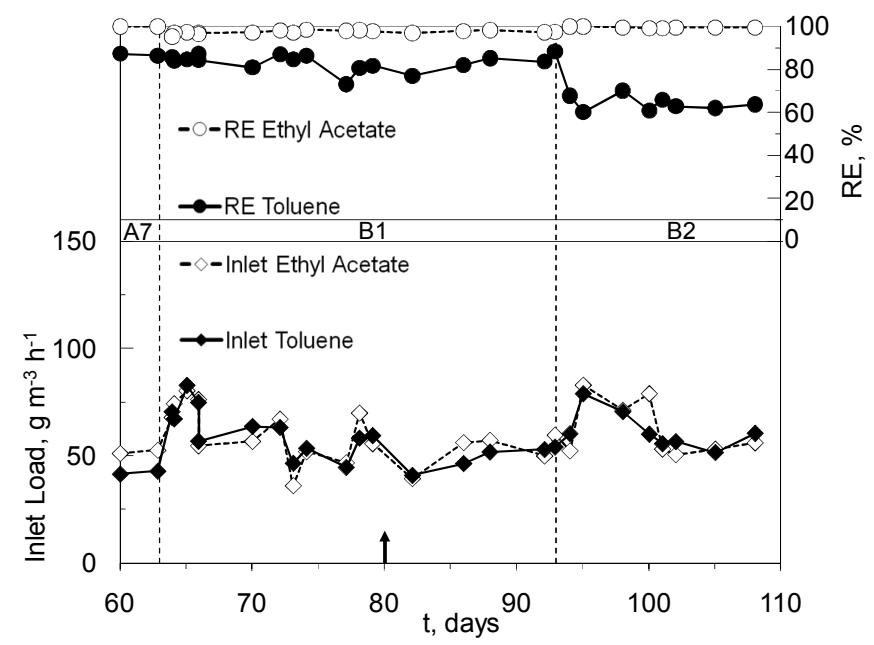

Figure 3. Monitoring of the membrane reactor performance at intermittent loading experiments. The arrow shows liquid recirculation replacing.

Monitoring $\mathrm{CO}_{2}$ production and outlet concentration of toluene were carried out after night and weekend closures in phases B1 and B2. As an example, the response of the MBR at restart after night and weekend closure periods during stage B1 is shown in Figure 4. GC analysis demonstrated that outlet emission was mainly composed of toluene $(>99 \%)$ during the entire test period in phases B1 and B2. Data from carbon dioxide production after overnight closures, plotted in Figures 4a showed that after a lag of about $15-30 \mathrm{~min}$, carbon dioxide production increased from values corresponding to endogenous metabolism to the stable total $\mathrm{CO}_{2}$ production in less than $1-2 \mathrm{~h}$ for night closures, however more time, around $12 \mathrm{~h}$, was necessary to reach stable $\mathrm{CO}_{2}$ production for weekend closures. Regarding toluene emissions, a continuous increase during $2 \mathrm{~h}$ was observed until stationary values were reached. 
a)

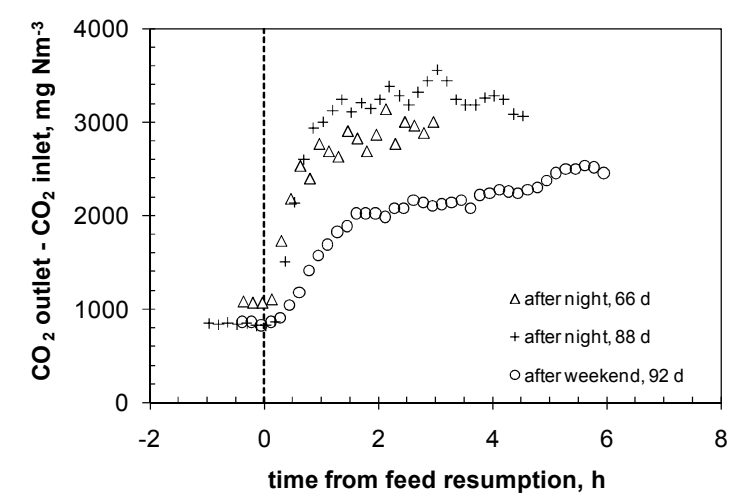

b)

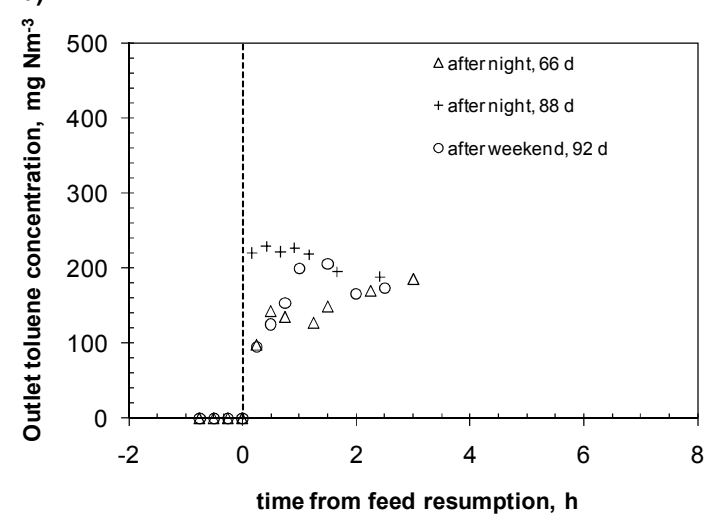

Figure 4. Immediate response of MBR at restart after night and weekend closure periods in stage B1. (a) Carbon dioxide production and (b) toluene emission.

Transient response to sudden shifts in inlet concentration is evaluated. On two different days during stage B2, the inlet VOC concentration was increased 1.5 and 2 times its baseline concentration $\left(1.0 \mathrm{~g} \mathrm{Nm}^{-3}\right)$. Results from monitoring toluene concentration at the outlet and total $\mathrm{CO}_{2}$ production are plotted in Figure 5. As in the previous experiments, it was corroborated that outlet emissions were only composed of toluene. For both shock tests, an increase in the pollutant breakthrough was developed in less than 25 minutes after the peak start; the performance of the MBR did not was significantly affected when the 1.5-fold inlet peak was applied. In all cases, increases in $\mathrm{CO}_{2}$ production were also observed. The $20-30$ minutes gap between end of the inlet peak and maximum $\mathrm{CO}_{2}$ emissions could indicate that microbial population needed some time to activate their metabolism under higher concentration of carbon source and part of VOC supplied during shock experiment is still absorbed inside the cells after the end of the peak.

a) 1.5-fold inlet peak

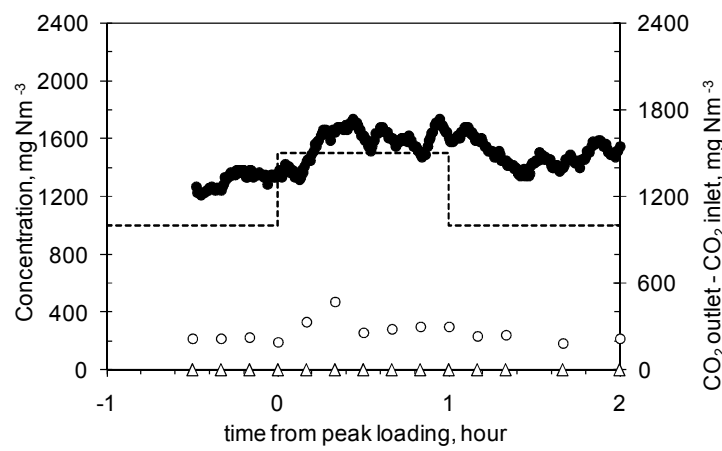

b) 2-fold inlet peak

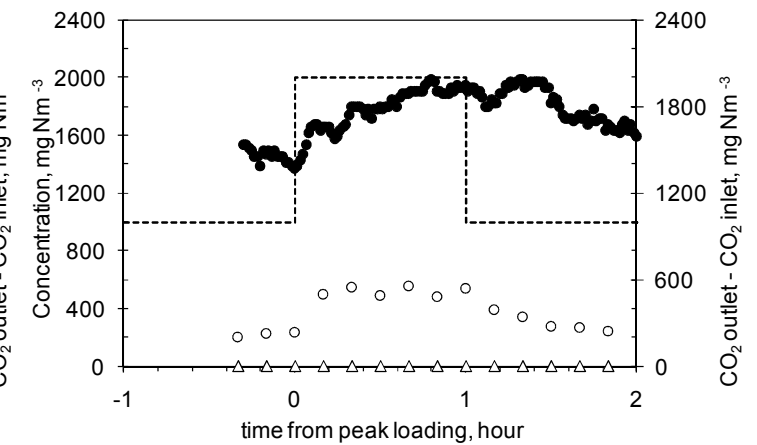

Figure 5. Response of MBR to inlet concentration peaks of (a) 1.5 and (b) 2 times its baseline concentration. $\mathrm{CO} 2$ production $(\Theta)$, total VOC concentration at the inlet (---) and at the outlet toluene $(\bigcirc)$ and outlet ethyl acetate $(\triangle)$.

\section{CONCLUSIONS}

This study illustrates the effective treatment by a lab-scale membrane bioreactor of waste gas polluted with a 1:1 ethyl acetate:toluene mixture under continuous and intermittent loading conditions. A maximum elimination capacity of $200 \mathrm{~g} \mathrm{~m}^{-3} \mathrm{~h}^{-1}$ (RE $100 \%$ ) for ethyl acetate was observed when the system was operated at an EBRT of 15 
$\mathrm{s}$, whereas a maximum elimination capacity of $75 \mathrm{~g} \mathrm{~m}^{-3} \mathrm{~h}^{-1}(\mathrm{RE} \sim 66 \%)$ at an EBRT of $60 \mathrm{~s}$ was obtained for toluene. Hexane was not degraded by the system when a 1:1:1 ethyl acetate:n-hexane:toluene was supplied, so that a specific bacteria consortium should be used. Similar removal was achieved operating in a $16 \mathrm{~h} \mathrm{day}^{-1}, 5$ days week ${ }^{-1}$ regular feed mode (at $100 \mathrm{~g} \mathrm{~m}^{-3} \mathrm{~h}^{-1}$ of instantaneous total IL and $30 \mathrm{~s}$ of EBRT) than in continuous loading. Night closures did not affect the RE, and $\mathrm{CO}_{2}$ production was restored in stable values in less than $1-2 \mathrm{~h}$. But in weekend closures, around $12 \mathrm{~h}$ was necessary to the $\mathrm{CO}_{2}$ production restoration. VOC emission was not detected in case of ethyl acetate. When inlet concentration peaks (1-h, 1.5- and 2-fold) were supplied, the presence of toluene resulted in high VOC emissions whereas ethyl acetate emissions were not detected.

\section{ACKNOWLEDGEMENTS}

F. J. Álvarez-Hornos acknowledges Ministerio de Educación, Spain, for providing a post-doctoral contract by means of Programa Nacional de Movilidad de Recursos Humanos del Plan Nacional de I+D+i 2008-2011.

\section{REFERENCES}

Álvarez-Hornos, F.J., Volckaert, D., Heynderickx, P.M. and Van Langenhove, H. (2011). Performance of a composite membrane bioreactor for the removal of ethyl acetate from waste air. Bioresour. Technol. doi: 10.1016/j.biortech.2011.06.064.

Attaway, H., Gooding, C.H. and Schmidt, M.G. (2001). Biodegradation of BTEX vapors in a silicone membrane bioreactor system. J. Ind. Microbiol. Biotechnol. 26: 316-325.

England, E., Fitch, M.W., Mormile, M. and Roberts, M.. (2005). Toluene removal in membrane bioreactors under recirculating and non-recirculating liquid conditions. Clean Technol. Environ. Policy. 7: 259-269.

European Commission. (2003). IPPC Reference Document on Best Available Techniques in Common Waste Water and Waste Gas Treatment/Management Systems in the Chemical Sector, Sevilla.

Devinny, J.S., Deshusses, M. and Webster, T.S. (1999). Biofiltration for air pollution control. Lewis Publishers/CRC Press, Boca Raton, ISBN: 9781566702898.

Ergas, S.J., Shumway, M., Fitch, M.W. and Neemann, J.J. (1999). Membrane process for biological treatment of contaminated gas streams. Biotechnol. Bioeng. 63: 431-441.

Hassan, A.A. and Sorial, G.A. (2010). Biofiltration of n-hexane in the presence of benzene vapors. J Chem Technol Biotechnol, 85: 371-377.

Kennes, C., Rene, E.R. and Veiga, M.C. (2009). Bioprocesses for air pollution control. J. Chem. Technol. Biotechnol. 84:1419-1436.

Kim, D. and Kim, H. (2005). Degradation of toluene vapor in a hydrophobic polyethylene hollow fiber membrane bioreactor with Pseudomonas putida, Process Biochem. 40: 20152020.

Koutinas, M., Martin, J., Peeva, L., Mantalaris, A. and Livingstone, A.G. (2006). An oil absorber bioscrubber system to stabilize biotreatment of pollutants present in waste gas. Fluctuating loads of 1,2 dichlorethane. Environ. Sci. Technol. 40: 595-602.

Kumar, A., Dewulf, J., Vercruyssen, A. and Van Langenhove, H. (2009). Performance of a composite membrane bioreactor treating toluene vapors: Inocula selection, reactor performance and behavior under transient conditions. Bioresour. Technol. 100: 2381-2387.

Kumar, A., Yuan, X., Ergas, S., Dewulf, J. and Van Langenhove, H. (2010). Model of a polyethylene microporous hollow-fiber membrane biofilm reactor inoculated with Pseudomonas putida strain To1 1A for gaseous toluene removal. Bioresour. Technol. 101: 2180-2184.

Mudliar, S., Giri, B., Padolev, K., Satpute, D., Dixit, R., Bhatt, P., Pandey, R., Juwarkar, A. and Vaidya, A. (2010). Bioreactors for treatment of VOCs and odours - A review. J. Environ. Manage. 91: 1039-1054. 